\title{
Incivility, Online Participation, and Message Delivery in the 2019 Hong Kong Protests: Exploring the Relationship
}

\author{
Gregory Gondwe ${ }^{1^{*}}$ \\ (iD) 0000-0001-7444-2731 K-5960-2019 \\ ${ }^{1}$ University of Colorado - Boulder, USA \\ * Corresponding author: grgo6314@colorado.edu
}

Citation: Gondwe, G. (2020). Incivility, Online Participation, and Message Delivery in the 2019 Hong Kong Protests: Exploring the Relationship. Online Journal of Communication and Media Technologies, 10(4), e202022. https://doi.org/10.30935/ojcmt/8397

\section{ARTICLE INFO}

Received: 19 May 2020

Accepted: 28 Jun 2020

\section{ABSTRACT}

This study used the 2019 online Hong Kong protests to understand whether negative messages serve as mediators between incivility and civic engagement, and to investigate whether incivility does trivialize the value of information and the message intended. The study sought to examine the impact of two types of incivility in online discourse on online participation and showed that the relationship is mediated by information value and message importance. Through 'netnographic' research, quasi-experiments, and online surveys, the findings were able to demonstrate that incivility (good) was necessary for increasing online participation, therefore, allowing negative messages to serve as mediators with indirect effects. The mediating effects were observed in the arousal of emotions that led to participation. Second, findings suggested that (good) incivility defined the importance of information and the content of the message.

Keywords: online protests, Facebook platforms, Hong Kong, information trivialization, incivility

\section{INTRODUCTION}

The 2019 Hong Kong protests in opposition to the contentious legislation (that would have allowed people accused of crimes to be sent to places with which Hong Kong had no extradition treaty, including mainland China where the courts are controlled by the Communist Party), brought to question the authenticity of the mainstream media in reporting political conflicts. As Cantoni et al. (2019) had observed, reports from mainstream media on the protests mostly concentrated on violent tactics, such as destroying public facilities and attacking police forces. Such variations in opinion led to skewed perceptions and conflicting messages about the protest, therefore creating and exacerbating homophily and polarization (Fok, 2017). For this reason, a number of people resorted to social media use for catharsis and engagement in the protests. Nonetheless, as it is in the nature of social media platforms during political conflicts, online incivility was among the common ingredients in the protest. Social media platforms such as the Hong Kong Protesters \& Global Politics, Hong Kong Protests 「香港抗議」\& the Hong Kong News even had cautions and questions that scrutinized the person before they joined their online platform nested on Facebook. Such an emphasis on civility online raises questions uncivil protests are bad by their very nature. In other words, can any good be attributed to incivility in online protests? What role does incivility play in promoting change?

\section{Aim of the Study}

We set out to first understand the relationship between online incivility during conflicts and the positive contributions to the protest. Essentially, the study aims at examining whether incivility has the capacity to contribute to positive outcomes in matters of conflict. By so doing, we debunk the conventional understanding that exposure to uncivil communication can hinder the democratic political process. Second, we challenge the underlying stimulation hypothesis argument that incivility stimulates negative behavior among online participants and the argument that communication with dissimilar others can encourage

Copyright (c) $\mathbf{2 0 2 0}$ by authors; licensee OJCMT. This article is an open access article distributed under the terms and conditions of the Creative Commons Attribution License (http://creativecommons.org/licenses/by/4.0/). 
incivility (Hopp \& Vargo, 2017). Particularly, we assert that the simulation hypothesis only explains the status quo and not the implications. The main threshold for our assertion is rooted in the argument that all liberal societies in history have, in one way or the other, depended on the wide adherence to norms of incivility to maintain hierarchies of social structure.

Our understanding of incivility in this study draws from Papacharissi (2004)'s dissection of the meaning and Calabrese's (2015) differentiation between what he calls as 'good' incivility vs bad incivility. According to Paracharissi, incivility can be understood as a conversational impoliteness, which is characterized by spontaneous emotional reactions, and as a collective impoliteness - a form of incivility that advances purposeful disregard for democratic consequences. We append a third form of impoliteness which we see as characterized by 'purposeful' regards for democratic consequences. On the other hand, Calabrese perceives incivility as falling under two categories: The first, that he calls 'good incivility' refers to some form of political communication that targets the message. Under such a kind, uncivil comments are targeted towards the underlying message in a comment. For example, in the case of Hong Kong, some uncivil posts and comments that target the policy and the status quo of the unfolding events would be considered as 'good incivility'. 'Bad incivility', on the other hand, refers to uncivil posts and comments that target a personality or assassinate character. With this in mind, we draw our further understanding of online incivility from experimental studies that manipulate derogatory terms and insulting language such as that of Wang and Silva (2018); and Anderson et al. (2016) to manipulate incivility. We employ both experimental designs, surveys, and 'Netnographic' research methods to investigate various types of online incivility while looking at effects and the intention to participate. Similar to existing studies that examine the effects of online incivility, we use a single topic of the Hong Kong protest to test our hypotheses.

Overarching, we do not assert that incivility is inherently good, but that it is necessary when used as a form of political communication for social justice. The call for online incivility is essentially a term used by powerful structures to intimidate and shut down voices that seek equality. As Arendt (1970) had asserted, violence (which in this case could be perceived in terms of online incivility) is a pre-condition for a mature political arena through which civil conversations occur. This was the idea of Fanon (2004) if understood in today's context. Arguably, Fanon would contend that 'incivility' or rather civil resistance begins within the crude parameters of the logic of what the powerful would refer to as civil. There is, he says, "a brutality of thought and mistrust of subtlety" (p.7) within the power structures that compel the citizens to rebel. This is because the weary roads to rational knowledge are transcended rather than merely inverted. "Truth is that which hurries on the break-up of the intimidating regimes of power; it is that which promotes the emergence of civil societies. Ideally, things are rethought in the light of the experience of struggle, of collective motion, regardless of it being civil or uncivil.

\section{Facebook in Hong Kong for Social Movements and Mobilization}

Social media as a whole has significantly contributed to the democratic engagement of civil societies. Several scholarly works on social protests and activist movements on the Internet support the view that indeed the Internet and ICTs are significantly influencing the ways activists communicate, collaborate and demonstrate (Asongu \& Nwachukwu, 2016; Howard et al., 2011; Khondkher, 2011). For Shirky (2011), social media have become coordinating tools for nearly all the world's political or protest movements. Thus, the Internet has enabled a networked population to gain greater access to information and more opportunities for collective action and increased freedom to demand change. Social media not only provide a platform for civil protests but also enables participants to express various their needs - things that matter most to them. As Chan and Fu (2017) had observed, while some participants in the online forums engaged in uncivil protests for its own sake, the needs of the people enabled participants to engage in 'narratives of belonging' (p. 444).

Facebook is still a threshold name for social media protests across the world. The ability to create a closed group forum/platform has allowed to bring together individuals pursuing the same goal. In Hongkong, Facebook serves a variety of facilitative roles, as Chan (2016) had observed. As he notes, "it is a carrier of information, a channel promoter, a meeting space for like-minded individuals, and most of all, it serves as a tool of mobilization (432). For example, the 2014 Occupy movement protests that brought together more that 100,000 people through posted messages, photos, and footage on Facebook attests to this importance. 
Facebook also gave rise to the iconic yellow umbrella symbol that many Facebook users used as their profile picture to express their support for the protests.

\section{LITERATURE REVIEW}

\section{Incivility as a Multifaceted Concept}

Incivility carries with it a negative connotation as it denotes a wide array of communicative and noncommunicative behaviors that range from rudeness and name-calling to vandalism and theft (Hopp \& Vargo, 2017). Coe, Kenski, and Rains (2004) in their study defined incivility as "features of discussion that convey an unnecessarily disrespectful tone toward the discussion forum, its participants, or its topics" (pg. 660). This is in line with Santana (2014) who later defined incivility as possessing one of the following characterizing features:(1) name-calling; (2) threats; (3) vulgarities; (4) abusive or foul language; (5) xenophobia; (6) hateful language, epithets or slurs; (7) racist or bigoted sentiments; (8) disparaging comments on the basis of race/ethnicity; and (9) use of stereotypes.

Santana (2014) tends to suggest that incivility cannot be denoted by a single behavior, that is why competing definitions of the term have emerged. The reality is that incivility is multifaceted and contextspecific in the sense that what one group or culture might consider as uncivil, another group or culture would still perceive it as civil. On the other hand, incivility, as a necessary evil mediates situations that ignore the needs of a healthy and civil society and used as "a blunt instrument to discipline and silence the weak, a manifestation of what Herbert Marcuse called, 'repressive tolerance' (Calabrese, 2015). As Marcuse (1969) had asserted in one of his seminal works, "Under the conditions prevailing in this country, tolerance does not, and cannot, fulfill the civilizing function attributed to it by the liberal protagonists of democracy, namely, the protection of dissent" (p. 117). Marcuse's statement draws to attention two approaches to both civility and incivility (the good one and the bad one). The emphasis here is the "good incivility" that pushes for a dialectic speech highlighting fundamental social ills of inequality, injustice, domination, and subordination as ascribed by Calabrese (p. 12).

Incivility seems to be a pushing narrative for civility, in this case, because civility by its nature derives a great deal of its power from the fact that the potential to deploy incivility is sometimes seen as a necessity. The mockery and insults used in uncivil conversations are equally essential for preserving the legitimacy of a given set of relations of domination and subordination (Calabrese, p. 12). This is because civility should only be understood as a means to an end and not as an end in itself and that civility is a lesser virtue than justice. The reality is that both civility and incivility can be used as a strategy to deceive the people, as in the case of the Bush administration that called for norms of civility from those who opposed the invasion of Iraq (Krugman, 2003)."

\section{Contextualizing Online Incivility}

Literature about online incivility stems from Habermas' (1989)'s deliberative ideals of a public sphere and the theory of the 'Market Place of Ideas'. Particularly, the marketplace of ideas holds that truth emanates from the competing ideas that are exercised in freedom and through public discourse and concludes that "ideas and ideologies will be culled according to their superiority or inferiority and widespread acceptance among the population". Whether this is true about today's online platforms is still a bone of contention. Many argue that most online conversations are not goal-oriented because they fail to evaluate specific policy decisions, and thus ending in mere talks and polarized ideas (Arendt, 1970; Dahlgren, 2005; Gondwe, 2018). Other scholars argue that dialogue as a deliberative process does not necessarily require a single formal structure to be important, but that it manifests in different forms and finer gradations of communication action that we are yet to know about (Black, 2008; Ferree et al., 2002; Wang \& Silva, 2018). Nonetheless, dialogue as a deliberative process only occurs in an environment open to the exchange and free flow ideas (McKeown \& Ladegaard, 2020). This environment is either civil or uncivil depending on who is defining it. For example, the U.S. National Institute for Civil Discourse (UNICP) defines civil discourse as "the free and respectful exchange of different ideas" regardless of whether each other agrees or disagrees with them. This, therefore, does not exclude the questioning and disputing of those opinions (McKeown \& Ladegaard, p. 2) only if done with respect. 
To a large extent, this definition pertains to the ideas of incivility as understood by Calabrese's approach to civility and justice. This is because incivility is perceived as upholding the discursive conditions under which individuals, in all their diversity, can speak and be heard in a language and formality that they know best. For this reason, incivility does not restrict individuals to hegemonic formal structures but allows them to be who they are and express themselves in a language of their competence. However, we acknowledge that there is also what we would refer to as bad-incivility. In this case, it only refers to some form of behavior that is targeted at muting the ongoing discourse. Most of such forms of bad-incivility target the person's reputation and not the discourse. Sometimes, the bad-incivility come in form of civility where a person commits a fallacy by appealing to civility, but only with an intention of shutting down the dialogue/discussant.

Under such an approach, for example, we construe explicit, bold disagreement as just impolite and not incivility. This is helpful because it helps us capture a wide array of incivility including that which some illintentioned users are deviously creating. Regardless, such an understanding still poses challenges to the operationalization of communication effects except when we choose to replicate processes that some existing studies had employed. Most of the existing studies limited the explanatory variables of incivility to polite and impolite behaviors in political discourses. Quantitatively done, the measure performed still fails to capture what would really be considered as polite vs. impolite. For example, how would they deal with rhetoric language? A number of scholars have suggested the measuring of media effects of those messages as a criterion for understanding what is polite vs. what is not (good-incivility vs. bad incivility). Particularly, media psychology suggests the employment of the biphasic model of emotions (Bradley \& Lang, 2000). This model connects "exposure to media to emotional responses, triggering pleasure and pain motivational systems" (Wang \& Silva, p. 76).

A number of studies have been done especially on bullying to show how emotions are triggered through unsavory social media interactions. However, other studies have equally shown how social media is in actual fact a catharsis for venting anger (Tandoc, Ferrucci, \& Duffy, 2015). Regardless of the kind of emotions participants get, both kinds of approaches are linked to deliberative processes. For example, Borah (2014) and Hopp and Vargo (2017) observe that negative online content does indeed lead to more online activity than positive content. Similarly, studies have also shown that emotionally charged messages spread faster and farther than non-emotionally charged messages (Stieglitz \& Dang-Xuan, 2013). Overarching, these two approaches to incivility bring about different emotional responses depending on the political party or country one is rooting for and the topic of each scenario. For example, in the Hong Kong protests, it would depend on whether one works for the government or not, or whether one is anti-mainland China or not. Given the split and the variations in emotions, we target first, incivility online and negative emotions. We ask the following question and hypothesize that:

RQ1: Negative messages in the 2019 Hong Kong online protests will serve as mediators between incivility and online participation?

H1: Negative messages will either positively or negatively mediate the relationship between incivility and online participation.

Rationale: Studies have shown that exposure to incivility in conflicts leads to negative emotions (Wang \& De Silva, 2018). However, what has not been substantiated is the role that these negative emotions play in mediating civility and incivility. This research question is, therefore, aimed at testing this argument by observing the tendencies in the 2019 Hong Kong protests. upsetting and engaging.

RQ2: Online incivility in the 2019 Hong Kong online protest trivialize the informational content of the intended message?

Rationale: Hypothetically we argue that most online incivility, when combined with civil engagement leads into what Habermas (1997) referred to as "Public Opinion", and thus, informed societies. We argue that incivility, in this case, is better than homophily in the sense that despite the kind of message content, people have the opportunity to engage in debates that result in informed decisions and conclusions. This is in opposition to Jamieson and Hardy (2012, p. 414), Hopp and Vargo (2017), and Anderson et al. (2016) whose findings suggested that incivility always elicits counterattack rather than substantive engagement), and that there is no deliberative democracy in 'uncivil' or negative political communication. We further argue that there 
is no significant or substantively important difference in agreement between individuals that viewed positive messages and those who viewed uncivil messages.

\section{METHOD}

\section{Sample Selection}

For this study, we collected data from Hong Kong online platforms nested on Facebook during a period of four months (August - November 2019). Two methodological approaches were used for data collection and analyses: Netnographic analysis and Quasi-Experiments to which we appended our surveys. Netnographic analysis is simply an online ethnographic approach that involves the researcher to immerse themselves into the online engagements. In this study, the researcher joined two major online platforms that were deeply engaged in the 2019 Hong Kong protests: The Hong Kong News (A Facebook forum with more than 80 million followers) and two Facebook platforms called the Hong Kong Protests 「香港抗議」 and the Hong Kong Protesters \& Global Politics, (with 7.1 million followers respectively). The researcher has been a member of these groups since August 2019, and actively participating in posts and comments.

\section{Recruitment survey participants}

Following Institutional Review Board approval, the data for this study were collected through an online survey that was hosted on Qualtrics. Convenience sampling was used after the researcher immersed themselves in an online ethnography. The researcher identified 500 active participants based on how frequent they posted or respondent to the posts and contacted directly by sending them an invitation to participate in the research. Of the 1000 contacted, 528 participants responded. However, of the 528 participants, only 227 participants were able to fill the questionnaire to our satisfaction. Nonetheless, the total response rate (calculated by dividing the number if complete questionnaires by the number of messages sent) provided adequate response rates for a survey without an incentive (5.6\% for Kang, 2010, is substantial).

Specifically, Participants were randomly selected with a purpose. As indicated above, the recruitment process for the 'to-be' survey respondents involved reaching out to active participants and requesting them to participate in the study. We first ask the respondents who were randomly selected (based on their engagement) some pre-test questions to determine their interests in participating in our study. Upon establishing that, we select the interested parties and present them with a manipulated stimulus of a past group post that seemed to trigger a lot of 'uncivil' conversations. We further adjusted the content and tone to trigger more participation by changing the language from civil to uncivil in both of our experimental posts. Finally, we matched the opinions of the participates with their already existing opinions from the same posts to determine whether there has been a change in perception. Participants that gave neutral responses were excluded from the study because we assumed that their levels of participation in our study that looked at whether information was neutral or not, would be skewed. This left us with a total of $\mathrm{N}=227$ viable respondents. Further, we blurred the names and pictures of all the selected participants to avoid confounding results.

\section{Experimental design and survey process}

Our experiments were quasi and done at several stages. Essentially, they involved the manipulation of the survey items. The participants were exposed to some stimuli involving Facebook posts that were deemed as uncivil. These posts and their content were originally posted on the same platforms by individuals from within the two groups. Under certain circumstances, we adjusted the posts to fit our criteria that were tested for reliability by two trained coders. The adjustments were made so as to make a clear distinction in the posts between what we considered as 'good incivility' and 'bad incivility'. As defined, we focused on who the message was targeting. The whole process involved the pre-and post-manipulation of the survey items. 


\section{Measurements}

\section{Incivility}

We limit our understanding of online incivility to messages that tend to arouse negative emotions. Wang and De Silva (2018) refer to these as insults and mockery. In a broad sense, we define incivility through the lenses of Santana (2014), Coe et al. (2014), and Papacharissi (2004). The measuring process of online incivility was computer-assisted. We generated an R-Script to detect incivility in the two online platforms. Using a dictionary of 100 words generated by three trained coders, the generated R-Script helped combine the matching words that were later humanly approved by looking at whether those words were indeed uncivil or not, and whether there were other words or phrases that the script had missed. In both cases, external validity exceeded 95 percent.

Next, we calculated incivility scores by summing the number of words that appeared in a post or comment that someone had made. Then we created a single aggregate index for incivility in each user's post or comment. We continued to derive the average incivility scores based upon what we considered as their normal patterns of interaction, ranging from 1 (very civil) to 7 (very uncivil). Our measurements indicated the aggregate average scores as $(M=0.29, S D=0.09$; Range $=0.04-0.22)$. To control for the effects of highly active Facebook users on the incivility measure, we calculated a measure that described the average number of posts/comments made by users on each social media platform. This gave us $(M=2.47, S D=2.33$; Range $=0.65$ - 7.0). By so doing, we were able to determine the average usage and participation, therefore, allowing us to eliminate the outliers in our sample and making our parameter estimates strong enough to explain the phenomenon. For this reason, the average of the population became our major sample.

\section{Emotions}

We measured emotions by averaging the participants' scores on a five-items that basically ask participants to rate their levels of emotion from normal anger to disgust on a Likert scale. This is in response to the posts presented to them. While this scale might be contested, a number of studies have used it and provided accurate information on emotions. For example, Wang and Silva's (2018) study was able to demonstrate the emotional variations between male and female participants when exposed to some experimental variables. Those items were drawn from Emotion Rating Scales (ERS) (McHugo et al., 1985) so as to respond to the needs of our current study. We created a Likert scale with response options ranging from "not at all" (1) to "extremely" (7), therefore yielding frameworks for understanding positive and negative emotions, as well as civil positive vs civil negative emotions. This approach replicates McHugo's process of analysis.

\section{Participation on the platform}

To determine participation, we further replicated Wang and Silva's (2018) approach that averaged the scores of all the participants on three items. These items asked each of the participants to rate the likelihood of completing three actions as follows: "posting a comment you initiated", "share the information you read about on the post with your friends," "Comment on the post," and "Like the post." The items were measured on a seven-point Likert scale from "very unlikely" (1) to "very likely" (7). This provided an average score of ( $\boldsymbol{\alpha}=$ $0.745, M=5.21, S D=1.47$ ). Since it was a quasi-experiment, we did not require manipulation checks.

\section{Information value and Message importance}

The value of information and the importance of the message were also determined by asking participants to indicate their perception on a 7-Likert scale. Drawing from Hirshleifer's (1973) attributes of information value and message importance, we asked the respondents to state the extent to which they agreed or disagreed to whether the information was useful to them, whether it made good suggestions, and whether it contained valuable ideas. For the message importance, the questions ranged from whether the arguments presented were justified to whether the importance was stated.

\section{Issue and trait}

Simply put, "Issue" and "Trait" are the yardsticks defining "good" and "bad" incivility respectively. Yet, some messages considered as 'uncivil' could contain an issue element. For example, cursing which is 'uncivil' in most 


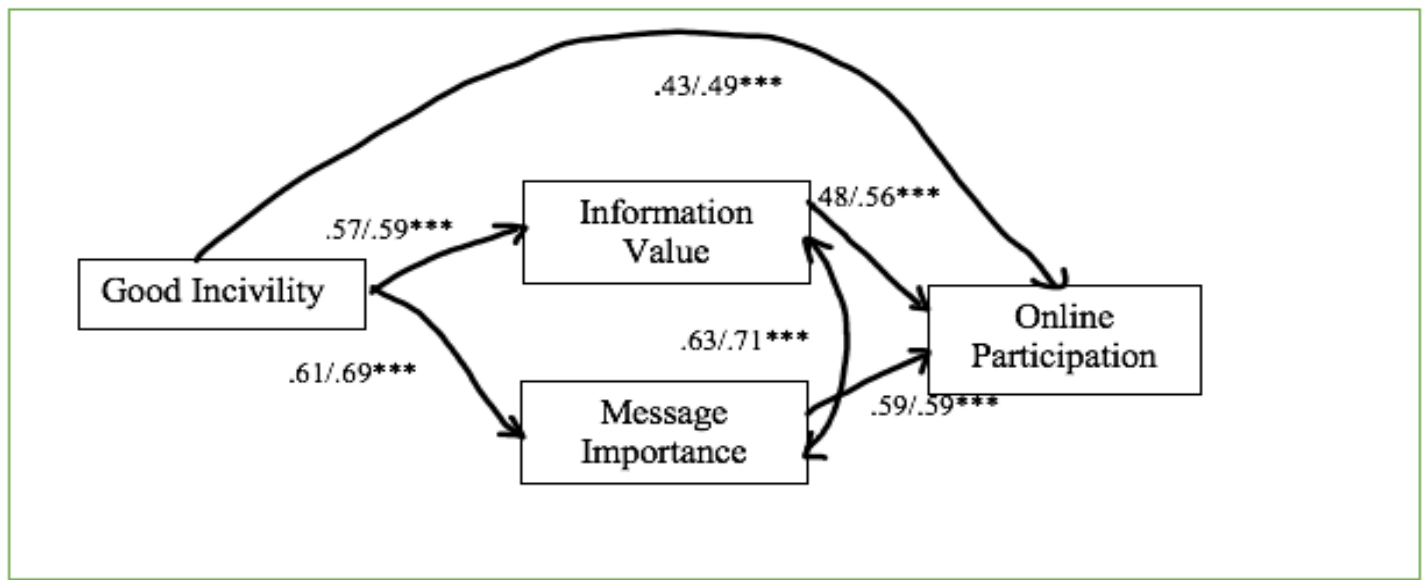

Figure 1. Unstandardized and standardized path coefficients of Good incivility

Note: $* p<.05, * * p<.01, * * * p<.001$

cases could still provide information that is either valuable or an important message. In this case, we would refer this as "Bad incivility \& Issue". Following the same logic, we could have "Bad Incivility \& trait" but also "Good incivility \& issue", as well as "Good incivility \& Trait."

\section{FINDINGS}

\section{Negative Messages in the 2019 Hong Kong Online Protests will Serve as Mediators between Incivility and Online Participation?}

Generally, the study aimed at predicting the effects of incivility (negative conversations online) in the 2019 Hong Kong protests. We began by running a confirmatory factor analysis using Bentler's (1993) ESQ software program. This imputed significant factor loadings at $p<.001$. We further entered our data in the ESQ program for analysis and designation of the direction and placement of our path coefficients. Our final model fit statistics $\left(\chi^{2}[6]=7.34, p=.12 ; C F I=1.00 ; N N F I=0.97 ; R M S E A=0.02\right)$, suggest that we satisfy the criteria for a good model fit as suggested by $\mathrm{Hu}$ and Bentler (1999). Our further tests and analyses for mediation found significant effects of online incivility in the Hong Kong Protests. Particularly, what was considered as uncivil forms of communication (i.e. insults and mockery) tended to fully mediate online participation, therefore reducing the direct effects of civility (from 0.47 to 0.19 upon mediators; $z=6.23, p<.001$ ) on what would be considered as dialogue or deliberative process. In this case, civility could not be established as having a direct effect on democratic and deliberative processes.

The mediation model was equally tested for indirect effects using Hayes' (2013) PROCESS Model 4. The findings suggest that incivility was associated with higher online participation $(B=0.548, S E=0.081, p<0.001)$ in the sense that individuals who strongly disagreed with the posts felt more compelled to respond to the post $(B=0.184$, SE $=0.078,95 \%$ C.I.; $0.083-0.426$ ). In other words, individuals who felt more negative about the uncivil political cross-cutting discussions of the Hong Kong online protests seemed to be more active for the sake of either justifying or correcting the perspective of the discourse. This was done with messages that many scholars such as Santana (2014), and Hopp and Vargo (2017) would define as incivility. The findings tend to support the general assumption of our first research question (RQ1) that aims at examining the mediation effects. And as mentioned above, the results indicate that increased incivility facilitated participation in the online Hong Kong protests. Figures 1 and 2 presents a summary of the findings. 


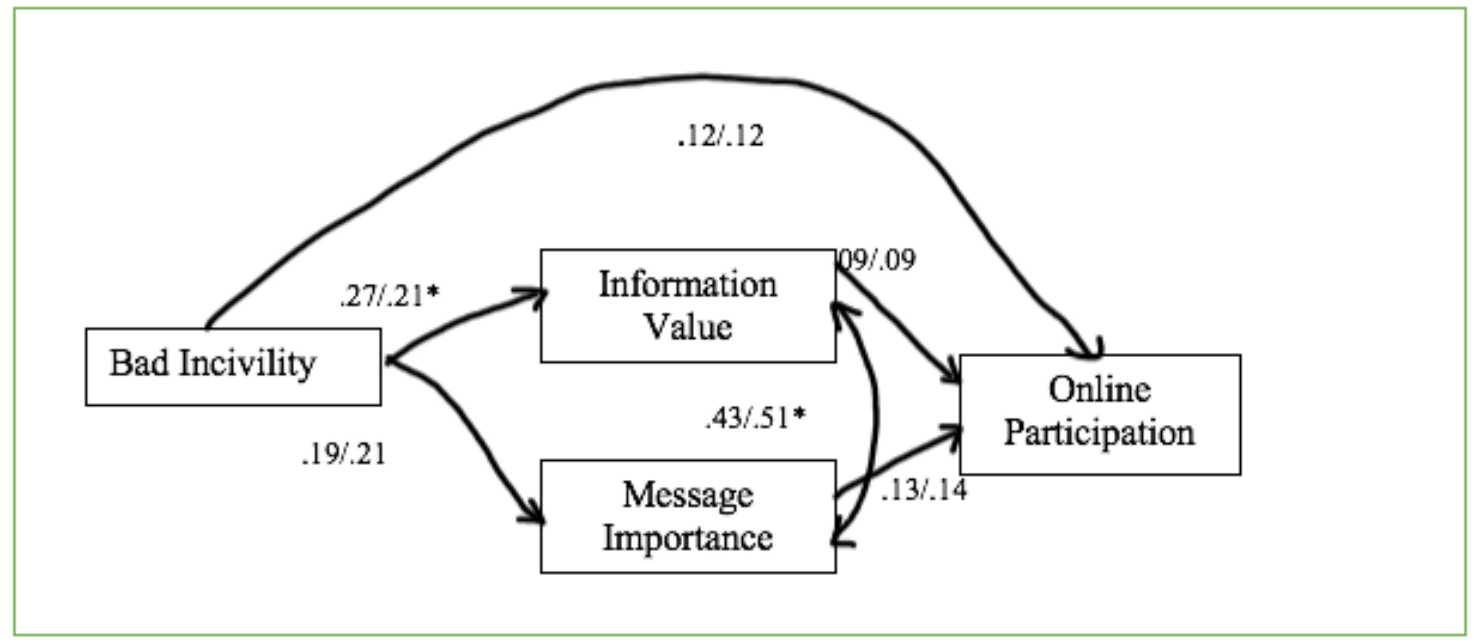

Figure 2. Unstandardized and standardized path coefficients of Bad incivility

Note: ${ }^{*} p<.05, * * p<.01, * * * p<.001$

\section{Online Incivility in the 2019 Hong Kong Online Protest will Trivialize the Informational Content of the Intended Message?}

RQ2 was examined by testing the main effects of tone in relation to the issue-trait dimensions in our data. We further measured the interaction effect of our data. Findings suggest that there were no statistically significant differences between individual participants who viewed the online posts as uncivil and those that viewed the message as civil communication. Further, incivility did not seem to be a criterion for individuals disagreeing with the message. Despite the fact that there seemed to be no statistical difference between messages of civility and incivility in relation to information and transformation towards positive change, $t(.2 .3$ on a 4-point scale), the interaction between tone and the trait versus issue dimension obscured a more substantial difference. On aggregate, participants were more likely to judge that issue-based messages (good incivility) raised more important concerns than trait-based (bad-incivility) information. In other words, issuebased messages were perceived as providing positive messages in the protests.

On the other hand, bad incivility was perceived as slightly less significant in the sense that it did actually have minimal indirect effects. In terms of ranking, 'good incivility' yielded more statistically significant effects than 'bad incivility' and 'civility'. In fact, positive messages were perceived to only mediate between good vs bad incivility. This suggests that people are more likely to see good incivility as more important than the same substantive message framed in a civil way. However, as soon as bad incivility is added to good incivility, the perceptions of its importance plummet. Similarly, good incivility was perceived to be statistically significant $(p<0.001)$ in effecting the proper deliverance of the intended message as well as promoting active participation. This, therefore, implies that civil conversation yielded less impact and less participation. Table 1 presents a summary of the findings.

Table 1 suggests that good incivility appeals are not only statistically significant as compared to all other types of messages but are substantively important as well. This is because participants perceive that the messages in good incivility vs bad incivility have different information values. For similar reasons as those discussed above with reference to informational value, the general expectation is that bad uncivil messages tend to be less informative than good uncivil messages, even when the informational content of the message is exactly the same. This relationship will be most marked for messages that are aimed at character assassinating messages since uncivil personal attacks will be perceived by the public to be the least informative. As in the case of message importance, the issue versus trait dimension obscures this relationship. Issue and trait messages, taken as a whole, are only moderately different, with scores of 3.21 and 3.17 , respectively. But in interaction with the negativity/incivility dimensions, issue-based messages are almost indistinguishable from one another (with only a maximum .03 spread between issue-based messages with the different types of tone). For trait-based messages, however, the effects of different types of tone are far 
Table 1. XPerceptions of information and message value

\begin{tabular}{lcc}
\hline & Informational Value of the message & Message Value importance \\
\hline Civil Positive & 3.26 & 3.73 \\
Civil Negative & 5.51 & 5.43 \\
Good Incivility & 6.62 & 6.15 \\
Bad Incivility & 3.98 & 4.17 \\
Good Incivility \& Issue & 3.24 & 3.47 \\
Bad Incivility \& Issue & 3.09 & 3.11 \\
Good incivility \& Trait & 3.77 & 3.36 \\
Bad Incivility \& Trait & 2.22 & 2.04 \\
& Scale: 7-point where 7
\end{tabular}

Note: A 7-point Likert scale was employed

more substantial. Good incivility trait-based messages have an average score of 3.24 on the informational value measure. Civil negative messages fare slightly, but not significant. However, it is bad incivility trait-based messages that are rated the lowest, with a mean score of 2.04. In other words, the only category that stands out as being notably worse in the interaction between negativity, incivility, and the issue versus trait dimensions for perceptions of informational value is uncivil negative trait-based messages. Incivility interferes with whether people think they learned something from the message, but only for trait-based messages.

These findings offer a consistent story in support of our study. Negativity per se is not perceived by the public as being a problem, and even uncivil attacks on issues do not provoke concern on the part of the public. The problem lies with the personal attacks, especially of the uncivil variety. Even when the substantive content of a message is exactly the same, the public perceives uncivil messages as being significantly less valuable than alternative forms of communication. These results, at this point, suggest the need to be more cautious in our worries about incivility. Uncivil attacks per se are not the problem; it is when it gets personal.

\section{DISCUSSION AND CONCLUSION}

The present study drew its population upon a corpus of more than 100 million possible participants from two online platforms nested on Facebook. A thorough analysis guided by netnographic approaches, quasiexperiments, and online pretests led to a sample of 127 viable participants. Given the scale of the data under consideration and the complexity of the understanding of online incivility, this study developed and applied a computer-automated technique for the identification of online incivility. The overall process employed a path analysis approach to test the mediating effects of positive civility, negative civility, good incivility and bad incivility within the context of the 2019 Hong Kong protests. This was done in effort of investigating the relationship between online incivility during conflicts and their contributions to the 2019 Hong Kong protests.

The overall results showed that good incivility (in the sense that it is not aimed at character assassination, but issue-based) positively predicted online participation. Incivility, in this case, tended to have an indirect effect on the intention to engage in online discussions. This implies that participation is fully mediated through negative emotional experiences - the more uncivil the conversation becomes, the more the number of participants increases. Particularly, our experiments and netnographic observations suggest that higher degrees of incivility in messages motivated participants to engage in the online discussions through liking the posts or commenting on the posts. This is inconsistent with the findings of Hopp and Vargo (2017), and Jamieson and Hardy (2012) who argue that uncivil comments "elicit counter-attack rather than substantive engagement." As Calabrese had argued, not all forms of incivility are equal. There is 'Bad' incivility and 'Good' incivility, leading to why Papacharissi advocates for separating civility from politeness and suggests that scholars "move away from a definition that relies on vocabulary, morality and simple good manners" (p. 265). From this perspective, we can draw the idea that good incivility, as opposed to bad incivility, could be ideological in the sense that people react to it when it challenges the status quo of their belief systems. As the findings suggest, participants in 'good incivility' messages indicated that they did not feel offended by the insults and mockery in the conversations in the sense that they seemed not to target a particular individual. Instead, they argued that they felt the mandate to educate those people through insults about the issue.

Second, in favor of our second research question, the findings suggested that 'good incivility is positively associated with the value of information and the importance of the message $(\beta=-.67)$. On the other hand, 
'bad' incivility was negatively associated with the same value of information and the importance of the message $(\beta=-.14)$. In other words, neither did civility or politeness correlate with the value of information. What this means is that incivility did not trivialize the informational content of the intended messages in the 2019 Hong Kong protests.

\section{CONCLUSION AND RECOMMENDATIONS}

These findings suggest a number of implications that can be summarized in the following arguments: First, that incivility is generally perceived in two forms - the bad one which simply attacks the character of the person and is damaging, and the good one which might include slurs that are only directed at the situation at hand. It is true that a few that feel uncomfortable with the language tend to withdraw from it. Second, that good incivility is inherently good when taken as a form of political communication. This is because it promotes engagement in light of Habermas' (1989) Public Sphere, where the majority are lured into the discussions so as to highlight the truth. This might, however, not settle well in conservative and religious cultures that tend to promote certain moral behavior. The question that still remains unanswered, therefore, is whether such cultures equally have a way that is closely related to 'good' incivility when it comes to promoting engagement.

Several limitations can be observed in this study. First, the sampling procedure and the nature of the data severely limits the generalizability of our findings. The source of data here, online social media platforms on Facebook about the Hong Kong protest is, at best, an instantaneous measure of behavior, not a durable measure of emotion or feelings as Viewed (2010) would argue. Moreover, Facebook platforms cannot be reasonably understood to be a directly reliable proxy for public opinion in general. While the findings still yield important conclusions toward discourse, democracy, and deliberative processes in times of conflict, we cannot use the current results to make generalizations about the role of incivility in other online protests. There will be a need to understand the nature of the protest and the cultural values that are into play.

\section{REFERENCES}

Anderson, A. A., Brossard, D., Scheufele, D. A., Xenos, M. A., \& Ladwig, P. (2014). The "nasty effect:" Online incivility and risk perceptions of emerging technologies. Journal of Computer-Mediated Communication, 19(3), 373-387. https://doi.org/10.1111/jcc4.12009

Arendt, H. (1970). On violence. Houghton Mifflin Harcourt.

Asongu, S. A., \& Nwachukwu, J. C. (2016). Revolution empirics: predicting the Arab Spring. Empirical Economics, 51(2), 439-482. https://doi.org/10.1007/s00181-015-1013-0

Bentler, P. (1993). EQS Structural equations program manual. Los Angeles, CA: BMDP Statistical Software.

Black, L. W. (2008). Deliberation, storytelling, and dialogic Moments: Deliberation, storytelling, and dialogic moments. Communication Theory, 18(1), 93e116. https://doi.org/10.1111/j.1468-2885.2007.00315.x

Borah, P. (2014). Interaction of incivility and news frames in the Political Blogosphere: Consequences and psychological. Handbook of Research on Political Activism in the Information Age, 407. https://doi.org/10.4018/978-1-4666-6066-3.ch024

Bradley, M. M., \& Lang, P. J. (2000). Measuring emotion: Behavior, feeling, and physiology. Cognitive neuroscience of emotion, 25, 49-59. https://doi.org/10.1016/0005-7916(94)90063-9

Calabrese, A. (2015). Liberalism's disease: Civility above justice. European Journal of Communication, 30(5), 539553. https://doi.org/10.1177/0267323115595306

Cantoni, D., Yang, D. Y., Yuchtman, N., \& Zhang, Y. J. (2019). Protests as strategic games: experimental evidence from Hong Kong's antiauthoritarian movement. The Quarterly Journal of Economics, 134(2), 1021-1077. https://doi.org/10.1093/qje/qjz002

Coe, K., Kenski, K., \& Rains, S. A. (2014). Online and uncivil? Patterns and determinants of incivility in newspaper website comments. Journal of Communication, 64(4), $658 \mathrm{e} 679$. https://doi.org/10.1111/jcom.12104

Dahlgren, P. (2005). The Internet, public spheres, and political communication: Dispersion and deliberation. Political communication, 22(2), 147-162. https://doi.org/10.1080/10584600590933160

Druckman, J. N., Gubitz, S. R., Lloyd, A. M., \& Levendusky, M. S. (2019). How Incivility on Partisan Media (De) Polarizes the Electorate. The Journal of Politics, 81(1), 291-295. https://doi.org/10.1086/699912 
Fanon, F. (2004). The Wretched of the Earth. 1961. Trans. Richard Philcox. New York: Grove.

Ferree, M. M., Gamson, W. A., Rucht, D., \& Gerhards, J. (2002). Shaping abortion discourse: Democracy and the public sphere in Germany and the United States. Cambridge University Press. https://doi.org/10.1017/CBO9780511613685

Fok, L. K. (2017). The Polarization and Civility of Hong Kong Political Discourse on Facebook News Pages.

Frazer, E., \& Hutchings, K. (2008). On politics and violence: Arendt Contra Fanon. Contemporary political theory, 7(1), 90-108. https://doi.org/10.1057/palgrave.cpt.9300328

Gondwe, G. (2018). News Believability \& Trustworthiness on African Online Networks: An Experimental Design. International Communication Research Journal, 53(2), 51-74

Habermas, J. (1997). The public sphere (pp. 105-108). na.

Hirshleifer, J. (1973, May). Where are we in the theory of information? The American Economic Review, 63(2). Papers and Proceedings of the Eighty-fifth Annual Meeting of the American Economic Association (pp. 31-39).

Hopp, T., \& Ferrucci, P. (2020). A Spherical Rendering of Deviant Information Resilience. Journalism \& Mass Communication Quarterly, 1077699020916428. https://doi.org/10.1177/1077699020916428

Hopp, T., \& Vargo, C. J. (2017). Does negative campaign advertising stimulate uncivil communication on social media? Measuring audience response using big data. Computers in Human Behavior, 68, 368-377. https://doi.org/10.1016/j.chb.2016.11.034

Howard, P. N., Duffy, A., Freelon, D., Hussain, M. M., Mari, W., \& Maziad, M. (2011). Opening closed regimes: what was the role of social media during the Arab Spring?. Available at SSRN 2595096. https://doi.org/10.2139/ssrn.2595096

Jamieson, K. H., \& Hardy, B. (2012). What is civil engaged argument and why does aspiring to it matter? PS: Political Science \& Politics, 45(3), 412-415. https://doi.org/10.1017/S1049096512000479

Khondker, H. H. (2011). Role of the new media in the Arab Spring. Globalizations, 8(5), 675-679. https://doi.org/10.1080/14747731.2011.621287

Krugman, P. (2003). Behind the great divide. The New York Times, 18.

Marcuse, H. (1969). An essay on liberation (Vol. 319). Beacon Press.

McHugo, G. J., Lanzetta, J. T., Sullivan, D. G., Masters, R. D., \& Englis, B. G. (1985). Emotional reactions to a political leader's expressive displays. Journal of personality and social psychology, 49(6), 1513. https://doi.org/10.1037/0022-3514.49.6.1513

McKeown, J., \& Ladegaard, H. J. (2020). Exploring the metadiscursive realization of incivility in TV news discourse. Discourse, Context \& Media, 33, 100367. https://doi.org/10.1016/j.dcm.2019.100367

Papacharissi, Z. (2004). Democracy online: Civility, politeness, and the democratic potential of online political discussion groups. New Media \& Society, 6(2), 259e283. https://doi.org/10.1177/1461444804041444

Santana, A. D. (2014). Virtuous or vitriolic: The effect of anonymity on civility in online newspaper reader comment boards. Journalism Practice, 8(1), 18-33. https://doi.org/10.1080/17512786.2013.813194

Stieglitz, S., \& Dang-Xuan, L. (2013). Emotions and information diffusion in social media-sentiment of microblogs and sharing behavior. Journal of management information systems, 29(4), 217-248. https://doi.org/10.2753/MIS0742-1222290408

Tandoc Jr, E. C., Ferrucci, P., \& Duffy, M. (2015). Facebook use, envy, and depression among college students: Is Facebooking depressing?. Computers in Human Behavior, 43, 139-146. https://doi.org/10.1016/j.chb.2014.10.053

Vieweg, S. (2010). Microblogged contributions to the emergency arena: Discovery, interpretation and implications. CSCW, February 6-10 (pp. 515-516). Savanah, GA: ACM. Retrieved from http://www.citeulike.org/user/ChaTo/article/6761693 [Google Scholar]

Wang, M. Y., \& Silva, D. E. (2018). A slap or a jab: An experiment on viewing uncivil political discussions on Facebook. Computers in human behavior, 81, 73-83. https://doi.org/10.1016/j.chb.2017.11.041

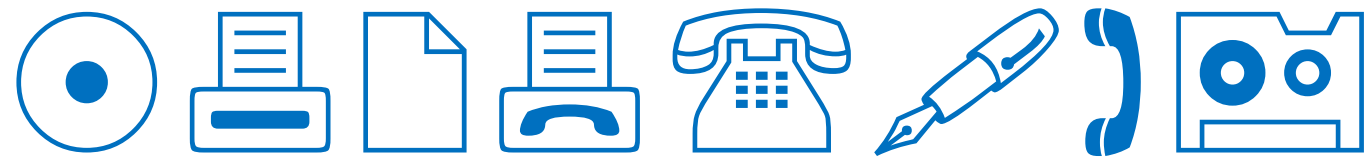

